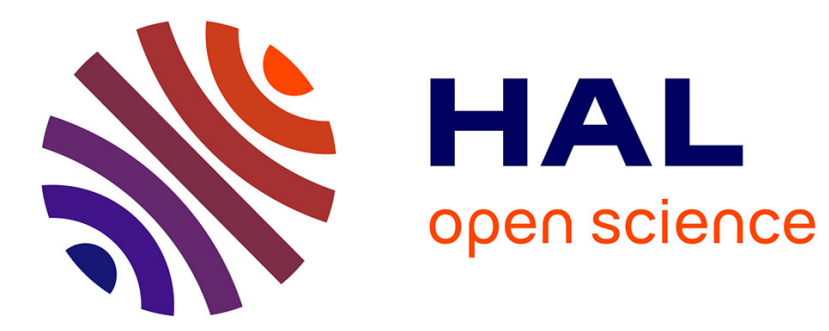

\title{
The energy band alignment of Si nanocrystals in $\mathrm{SiO} 2$
}

\author{
G. Seguini, Sylvie Schamm-Chardon, P. Pellegrino, M. Perego
}

\section{To cite this version:}

G. Seguini, Sylvie Schamm-Chardon, P. Pellegrino, M. Perego. The energy band alignment of Si nanocrystals in SiO2. Applied Physics Letters, 2011, 99 (8), pp.082107. 10.1063/1.3629813 . hal01745021

\section{HAL Id: hal-01745021 \\ https://hal.science/hal-01745021}

Submitted on 9 Apr 2018

HAL is a multi-disciplinary open access archive for the deposit and dissemination of scientific research documents, whether they are published or not. The documents may come from teaching and research institutions in France or abroad, or from public or private research centers.
L'archive ouverte pluridisciplinaire HAL, est destinée au dépôt et à la diffusion de documents scientifiques de niveau recherche, publiés ou non, émanant des établissements d'enseignement et de recherche français ou étrangers, des laboratoires publics ou privés. 


\section{The energy band alignment of $\mathrm{Si}$ nanocrystals in $\mathrm{SiO}_{2}$}

G. Seguini, S. Schamm-Chardon, P. Pellegrino, and M. Perego

Citation: Appl. Phys. Lett. 99, 082107 (2011); doi: 10.1063/1.3629813

View online: https://doi.org/10.1063/1.3629813

View Table of Contents: http://aip.scitation.org/toc/apl/99/8

Published by the American Institute of Physics

\section{Articles you may be interested in}

Scaling size of the interplay between quantum confinement and surface related effects in nanostructured silicon Applied Physics Letters 103, 023103 (2013); 10.1063/1.4813743

Size-controlled highly luminescent silicon nanocrystals: $\mathrm{A} \mathrm{SiO} / \mathrm{SiO}_{2}$ superlattice approach Applied Physics Letters 80, 661 (2002); 10.1063/1.1433906

Silicon quantum wire array fabrication by electrochemical and chemical dissolution of wafers Applied Physics Letters 57, 1046 (1990); 10.1063/1.103561

Quantum confinement in Si and Ge nanostructures: Theory and experiment Applied Physics Reviews 1, 011302 (2014); 10.1063/1.4835095

Charge transport in $\mathrm{Si}$ nanocrystal/ $\mathrm{SiO}_{2}$ superlattices Journal of Applied Physics 113, 133703 (2013); 10.1063/1.4798395

Si nanocrystal based memories: Effect of the nanocrystal density Journal of Applied Physics 100, 014310 (2006); 10.1063/1.2214300

\section{Scilight} Sharp, quick summaries illuminating the latest physics research 


\title{
The energy band alignment of $\mathrm{Si}$ nanocrystals in $\mathrm{SiO}_{2}$
}

\author{
G. Seguini, ${ }^{1, a)}$ S. Schamm-Chardon, ${ }^{2}$ P. Pellegrino, ${ }^{3}$ and M. Perego ${ }^{1}$ \\ ${ }^{1}$ Laboratorio MDM, IMM-CNR, Via C. Olivetti 2, 20864 Agrate Brianza (MB), Italy \\ ${ }^{2}$ CEMES-CNRS and Université de Toulouse, nMat group, BP94345, 31055 Toulouse, Cedex 4, France \\ ${ }^{3}$ MIND, IN2UB, Universitat de Barcelona, C/Martì i Franquès 1, E-08028 Barcelona, Catalunya, Spain
}

(Received 1 July 2011; accepted 5 August 2011; published online 25 August 2011)

\begin{abstract}
The determination of the energy band alignment between the 2.6-nm-diameter Si nanocrystals and the $\mathrm{SiO}_{2}$ host is achieved by means of photo-ionization/-neutralization and capacitance spectroscopy. The measured conduction and valence band offsets are $2.6 \mathrm{eV}$ and $4.4 \mathrm{eV}$. The band gap is evaluated to be $1.7 \mathrm{eV}$ by photoluminescence. These results indicate that the valence band offset at the $\mathrm{Si}$ nanocrystals $/ \mathrm{SiO}_{2}$ interface is quite close to the one observed at bulk $\mathrm{Si} / \mathrm{SiO}_{2}$ interface. On the contrary, we observe a clear upward shift $(0.5 \mathrm{eV})$ of the conduction band in the $\mathrm{Si}$ nanocrystals $/ \mathrm{SiO}_{2}$ system with respect to the bulk $\mathrm{Si} / \mathrm{SiO}_{2}$ hetero-structure. (C) 2011 American Institute of Physics. [doi:10.1063/1.3629813]
\end{abstract}

Si nanocrystals (ncs) embedded in oxide host have been intensively studied both to investigate the properties of the matter at nanometric scale and for nanoelectronic, optoelectronic, and photovoltaic applications. ${ }^{1-4}$ The band gap of $\mathrm{Si}$ ncs increases when their size shrinks. Several theoretical works described this issue ${ }^{5}$ and different optical techniques as photoluminescence (PL), spectroscopic ellissometry, and optical absorption have been used to prove this fact. ${ }^{6-8}$ On the other hand, in the perspective of the technological applications, a lot of works has been carried out on the electrical characteristics, in particular related to the charge trapping properties of the $\mathrm{Si}$ ncs based metal-oxide-semiconductor (MOS) structures. 9 Among these wide characterization efforts, the direct measurement of the Si ncs energy alignment in the $\mathrm{SiO}_{2}$ host is still lacking. The present work is focused on the experimental determination of the energy band alignment of $\mathrm{Si}$ ncs in a $\mathrm{SiO}_{2}$ matrix. This goal is achieved through the measurement of their conduction band (CB) and valence band (VB) energy positions in the $\mathrm{SiO}_{2}$ host compared to the bulk $\mathrm{Si} / \mathrm{SiO}_{2}$ interface energy barriers.

The band alignment at the bulk Si/oxide interface is usually characterized by means of internal photoemission or $\mathrm{x}$ ray photoelectron spectroscopy. ${ }^{10-15}$ Differently, in the case of the $\mathrm{Si}$ ncs embedded in $\mathrm{SiO}_{2}$ matrix, these techniques are not reliable, due to the overlap of the signals of the Si ncs with those of the $\mathrm{Si} / \mathrm{SiO}_{2}$ interface. Therefore, in order to single out the effects due to the $\mathrm{Si}$ ncs, the variations of the charging state of the Si ncs upon different, electrical or optical, stress were addressed as a key property to investigate the $\mathrm{Si}$ ncs band alignment. We integrate the information obtained by PL on the Si ncs average band gap with the measurements of the VB shift $(\triangle \mathrm{VB})$ obtained by photo-ionization (PI) ${ }^{16,17}$ and those of the $\mathrm{CB}$ shift $(\triangle \mathrm{CB})$ measured by photo-neutralization $(\mathrm{PN})^{16,17}$ and capacitance spectroscopy (C-S). ${ }^{18}$ The overall results allow obtaining a consistent description of the energy band alignment of $\mathrm{Si}$ ncs in $\mathrm{SiO}_{2}$.

$\mathrm{SiO}_{2} / \mathrm{SiO} / \mathrm{SiO}_{2}$ multilayer structures were fabricated by subsequent $\mathrm{SiO}$ and $\mathrm{SiO}_{2}$ depositions in an electron-beam evaporation system without breaking the high vacuum (base

${ }^{a)}$ Electronic mail: gabriele.seguini@mdm.imm.cnr.it. pressure $5 \times 10^{-7}$ mbar) regime to avoid interfaces contamination. A 6-nm-thick $\mathrm{SiO}$ layer was deposited between a 3nm-thick $\mathrm{SiO}_{2}$ layer, tunnel oxide (TO) and a 10-nm-thick $\mathrm{SiO}_{2}$ layer, blocking oxide (BO). Prior to the deposition all the n-type, 1-5 $\Omega \mathrm{cm}$, Si (100) substrates were dipped in HF solution to obtain a clean surface. A 15 -nm-thick $\mathrm{SiO}_{2}$ reference sample was deposited without any $\mathrm{SiO}$ interlayer. To promote the formation of the $\mathrm{Si}$ ncs, all the samples were annealed in a conventional quartz-tube furnace at $1050^{\circ} \mathrm{C}$ for $1800 \mathrm{~s}$ in a $\mathrm{N}_{2}$ flux. ${ }^{9,19}$ Finally, all the samples were annealed in forming gas, $\mathrm{H}_{2}: \mathrm{N}_{2}$, for $900 \mathrm{~s}$ at $400{ }^{\circ} \mathrm{C}$ in a rapid thermal processing machine. MOS capacitors were fabricated by thermally evaporating semitransparent $\mathrm{Al}$ (15-nm-thick) circular electrodes $\left(0.08 \mathrm{~mm}^{2}\right.$ area) through a shadow mask as the top gate and 100-nm-thick $\mathrm{Al}$ as the bottom electrode.

The $\mathrm{Si}$ ncs formation in the $\mathrm{SiO}_{2}$ host was investigated by means of high resolution electron microscopy and energy filtered transmission electron microscopy. ${ }^{20}$ These measurements corroborated the full crystalline character of the $\mathrm{Si}$ nanoclusters and provided the thickness of the stack after the thermal treatment. The $\mathrm{SiO}_{2} \mathrm{TO}$ and $\mathrm{BO}$ were determined to be $5.3 \pm 0.3 \mathrm{~nm}$ and $10.9 \pm 0.5 \mathrm{~nm}$ thick, respectively. The mean diameter of the Si ncs was $2.6 \pm 0.1 \mathrm{~nm}$. The average ncs density is in the order of $10^{11}-10^{12} \mathrm{~cm}^{-2}$. The evaluation of the Si ncs average band gap was achieved by PL. The spectra were acquired using an Ar laser for excitation $(\lambda=488$ $\mathrm{nm})$. A strong emission band peaked around $1.45 \pm 0.05 \mathrm{eV}$ was found, in agreement with data reported in the literature. $^{7,8,19}$ As noticed by Garrido et al., ${ }^{7}$ the emission energy is affected by a Stokes shift of $0.26 \pm 0.03 \mathrm{eV}$ with respect to the absorption energy irrespective of the size of the Si ncs. Taking in account this effect, the optical band gap of the Si ncs embedded in $\mathrm{SiO}_{2}$ matrix was evaluated to be $1.7 \pm 0.1 \mathrm{eV}$.

Both PI/PN and C-S measurements capacitively detect the localized charges in the Si ncs by monitoring the shift of the flat band voltage $\left(V_{F B}\right)$ in capacitance-voltage $(\mathrm{CV})$ curves. The $\mathrm{CV}$ curves were acquired sweeping the applied voltage between inversion to accumulation at $100 \mathrm{KHz}$ in a dark environment in a shielded probe station. A $150 \mathrm{~W} \mathrm{Xe}$ arc lamp was used as the radiation source for PI/PN measurements. The photon spectral range was $h v=2.0-6.0 \mathrm{eV}$ while 
the incident photon flux $\left(n_{p h}\right)$ was measured using a $\mathrm{Si}$ photodiode. $^{11}$

During PI measurements (Fig. 1, inset), the transition of the $\mathrm{Si}$ ncs from the neutral to the positive state was caused by an optical excitation of the electrons from the Si ncs VB to the $\mathrm{SiO}_{2} \mathrm{CB}$. The samples were illuminated with monochromatic photons for $\Delta t=300 \mathrm{~s}$ with a positive applied voltage $(V=+1.5 \mathrm{~V})$ to collect the excited electrons at the metal gate. Subsequently, a CV curve was acquired in darkness to measure the $V_{F B}$ position. This procedure was repeated at different photon energy values ranging from 2.0 to $6.0 \mathrm{eV}$ with step of $0.1 \mathrm{eV}$ to monitor the $V_{F B}$ evolution as function of the photon energy. The same analysis was performed during PN measurements (Fig. 2, inset) on Si ncs that were preliminarily charged by electrons tunnelling through the $\mathrm{SiO}_{2}$ potential barrier from the substrate, applying a suitable dc bias $(+9 \mathrm{~V}, 5 \mathrm{~s})$. In this case, the monochromatic light irradiation induced the transition of the Si ncs from the initial negative state to a neutral state, due to the optical excitation of electrons from the Si ncs $\mathrm{CB}$ to the $\mathrm{SiO}_{2} \mathrm{CB}$.

From the shift of the $V_{F B}$ with respect to the initial state $\left(\Delta V_{F B}\right)$, we determined the charge variation $\Delta V_{F B} * C_{O X}$ (where $C_{O X}$ is the capacitance of the device per $\mathrm{cm}^{2}$ ) in the Si ncs as a function of $h v$. Normalizing on the number of incident photon $n_{p h} * \Delta t$, we calculated the relative quantum yield $(Y)$ which is defined as

$$
Y=\frac{\Delta V_{F B} * C_{O X}}{n_{p h} * \Delta t} .
$$

The extrapolation of $Y^{1 / 2}$ to zero yield allows the determination of the different barrier energies during ionization and neutralization processes. ${ }^{16,17}$

In Fig. 1 (left axis), the $V_{F B}$ evolution during PI measurements is reported. The $V_{F B}$ shifts towards negative values for photon energies above $\sim 4 \mathrm{eV}$, indicating that, above this threshold, negative charges are extracted from the $\mathrm{Si}$ ncs. The extrapolation of the calculated $Y^{1 / 2}$ to zero yield is depicted in Fig. 1 (right axis). The barrier energy for the ionization process, from the $\mathrm{Si}$ ncs $\mathrm{VB}$ to the $\mathrm{SiO}_{2} \mathrm{CB}$, was found to be $4.5 \pm 0.1 \mathrm{eV}$. By considering a $\mathrm{SiO}_{2}$ band gap of $8.9 \pm 0.1 \mathrm{eV}$, the VB offset between the $\mathrm{Si}$ ncs and the $\mathrm{SiO}_{2}$ results to be $4.4 \pm 0.1 \mathrm{eV}$. The magnitude of the energy transition corresponding to the ionization process at the bulk $\mathrm{Si}$ /

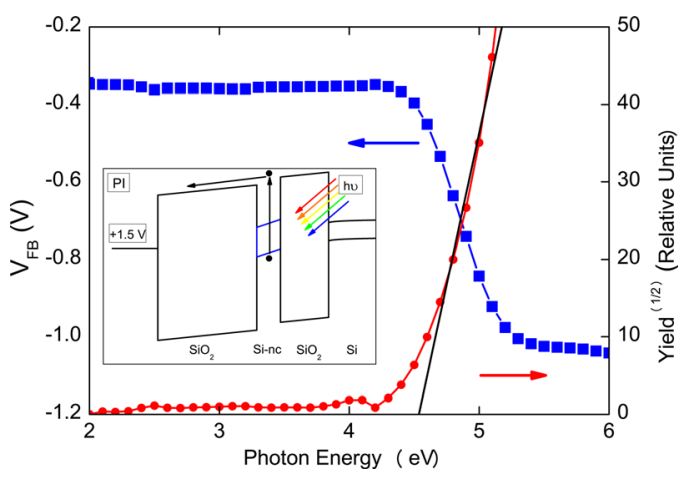

FIG. 1. (Color online) (Left, blue square) $V_{F B}$ as function of the photon energy for Si ncs MOS based device after different monochromatic photon energy irradiation (from $2.0 \mathrm{eV}$ to $6.0 \mathrm{eV}$, step $0.1 \mathrm{eV}$ ) for $300 \mathrm{~s}$ under positive $(+1.5 \mathrm{~V})$ bias. (Right, red circle) $Y^{1 / 2}$ as function of the photon energy for the same process. (Inset) Band diagram of the PI transition involved.

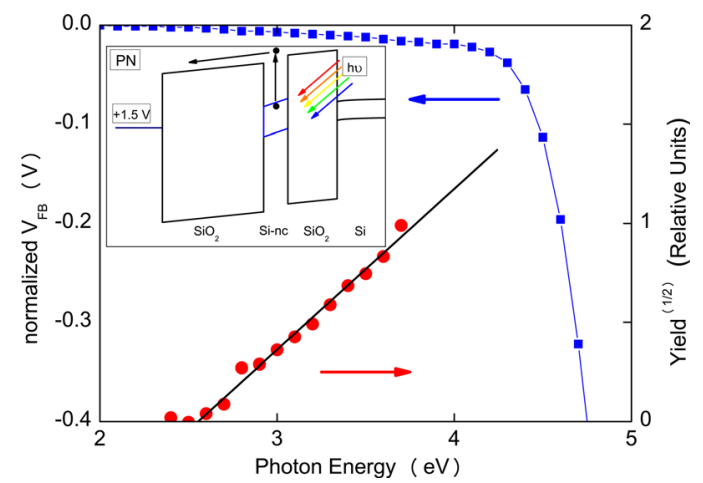

FIG. 2. (Color online) (Left, blue square) Normalized $V_{F B}$ as function of the photon energy for PN spectra of previously charged (+9 V, $5 \mathrm{~s}$ ) Si ncs MOS based device after different monochromatic photon energy irradiation (from $2.0 \mathrm{eV}$ to $6.0 \mathrm{eV}$, step $0.1 \mathrm{eV}$ ) for $300 \mathrm{~s}$ under positive $(+1.5 \mathrm{~V})$ bias. (Right, red circle) $Y^{1 / 2}$ versus incident photon energy for the same process. (Inset) Band diagram of the $\mathrm{PN}$ transitions involved.

$\mathrm{SiO}_{2}$ interface is $4.3 \pm 0.1 \mathrm{eV} .^{15}$ The difference among these values results in a $\triangle \mathrm{VB}$ of $0.2 \pm 0.1 \mathrm{eV}$ between the Si ncs embedded in the $\mathrm{SiO}_{2}$ matrix and the bulk Si substrate.

In Fig. 2 (left axis), the $V_{F B}$ evolution during PN measurements is reported. In order to remove all the artefacts related to the detrapping effects occurring in darkness, the reported $V_{F B}$ values were corrected by the subtraction of the corresponding $V_{F B}$ values acquired under the same experimental condition but without monochromatic light irradiation. As observed in the PI spectra, there is a clear onset in the $V_{F B}$ curve for photon energies above $\sim 4 \mathrm{eV}$, due to the transition of electrons from the $\mathrm{Si}$ ncs VB to the $\mathrm{SiO}_{2} \mathrm{CB}$. In addition, we observed a clear light induced $V_{F B}$ variation for photon energy below $4 \mathrm{eV}$. The calculated $Y^{1 / 2}$ for $h v$ values ranging from $2 \mathrm{eV}$ to $4 \mathrm{eV}$ is depicted in Fig. 2 (right axis). By means of the $Y^{1 / 2}$ extrapolation to zero yield, a barrier energy value of $2.6 \pm 0.1 \mathrm{eV}$ was extracted for the neutralization process. This barrier corresponds to the $\mathrm{CB}$ offset between the $\mathrm{Si}$ ncs and the $\mathrm{SiO}_{2}$. The $\mathrm{CB}$ offset at the bulk $\mathrm{Si} / \mathrm{SiO}_{2}$ interface is $3.1 \pm 0.1 \mathrm{eV}$ (Ref. $15)$ and so the resulting $\triangle \mathrm{CB}$ value is $0.5 \pm 0.1 \mathrm{eV}$.

The $\triangle \mathrm{CB}$ was measured by $\mathrm{C}-\mathrm{S}$ as well. By this technique, electrons were electrically injected in the $\mathrm{Si}$ ncs by means of a positive dc bias $\left(V_{I N J}\right)$ applied to the metal gate for $1 \mathrm{~s} .{ }^{18}$ When the $V_{I N J}$ is high enough, the lowest CB level of the $\mathrm{Si}$ ncs coincides with the $\mathrm{CB}$ of the Si substrate and electrons start to tunnel from the $\mathrm{Si}$ substrate into the $\mathrm{Si}$ ncs through the $\mathrm{SiO}_{2}$ potential barrier. The trapping of negative charges in the $\mathrm{Si}$ ncs results in a positive shift of the $V_{F B}$. In the inset of Fig. 3, we report the $\mathrm{C}-\mathrm{V}$ curves acquired at different $V_{I N J}$ values in the $1-9 \mathrm{~V}$ range with steps of $1 \mathrm{~V}$. A rigid shift of the C-V curves is observed for $V_{I N J}$ values above $5 \mathrm{~V}$ due to the injection of negative charges in the Si ncs. In Fig. 3 , we reported the evolution of the $V_{F B}$ as a function of $V_{I N J}$. From this curve, the threshold voltage $\left(V_{T H}\right)$ at which a sizeable charging begins to occur was determined by linear extrapolation. The $V_{T H}$ was found to be $5.85 \pm 0.05 \mathrm{~V}$.

As reported by Cho et al., ${ }^{18}$ the value of $\Delta \mathrm{CB} / e$, where $e$ is the elementary charge, corresponds to the potential drop across the Si ncs $\left(V_{n c}\right)$ at $V_{I N J}=V_{T H} . V_{n c}$ can be defined as

$$
V_{n c}=d f * V_{O X} .
$$

The dielectric factor $(d f)^{21}$ is given by 


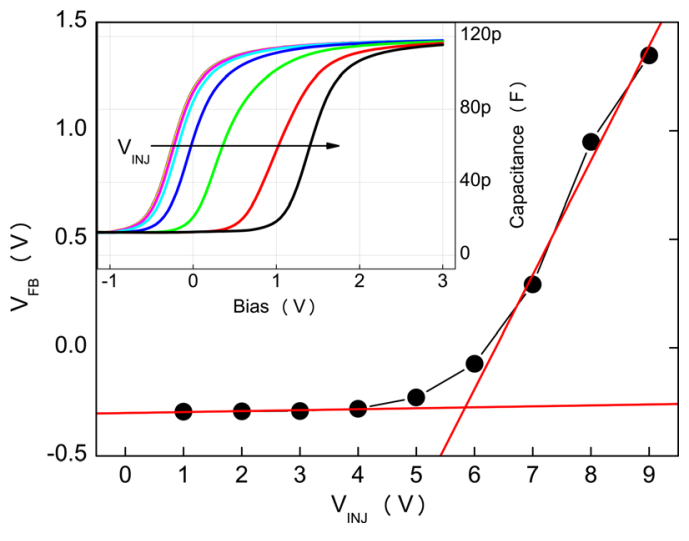

FIG. 3. (Color online) $V_{F B}$ as function of the $V_{I N J}$. (Inset) $\mathrm{CV}$ characteristic of Si ncs MOS based device after charging achieved by different applied $V_{I N J}$ before the sweep (from $1 \mathrm{~V}$ to $9 \mathrm{~V}$, step $1 \mathrm{~V}, 1 \mathrm{~s}$ ).

$$
d f=\frac{\frac{d}{\varepsilon_{S i}}}{\frac{t_{B O}}{\varepsilon_{B O}}+\frac{d}{\varepsilon_{S i}}+\frac{t_{T O}}{\varepsilon_{T O}}} *(1.806-0.0241 * d),
$$

where $d, t_{B O}$, and $t_{T O}$ are the diameter of Si nc, the thickness of the $\mathrm{BO}$, and of the $\mathrm{TO}$ in nanometers, respectively; $\varepsilon_{S i}$, $\varepsilon_{B O}$, and $\varepsilon_{T O}$ are the relative permittivity of the $\mathrm{Si}(11.9)$ and of the BO and TO (3.9), respectively. $V_{O X}$ is defined as the potential drop across the total dielectric between the Si substrate and the metal gate that is given by

$$
V_{O X}=V_{I N J}-V_{F B}-\psi_{S},
$$

where $\psi_{S}$ is the potential drop across the Si substrate which is obtained by solving Poisson's equations at $V_{I N J}=V_{T H}{ }^{22,23}$ According to this model, the above reported $V_{T H}$ value results in a $\triangle \mathrm{CB}$ of $0.5 \pm 0.1 \mathrm{eV}$, in perfect agreement with the $\mathrm{PN}$ results.

The same PI/PN and C-S measurements were performed on the annealed 15-nm-thick $\mathrm{SiO}_{2}$ sample under the same experimental conditions. Interestingly, no detectable $V_{F B}$ shift was observed in this reference sample. Thus, the previously reported $V_{F B}$ variations are unambiguously related to charge trapping/detrapping phenomena occurring in the Si ncs embedded in the $\mathrm{SiO}_{2}$ matrix.

Figure 4 summarizes the energy band alignment for Si ncs of $2.6 \mathrm{~nm}$ of diameter embedded in $\mathrm{SiO}_{2}$ host. It is interesting to note that the overall gap obtained by adding the evaluated $\Delta \mathrm{CB}(0.5 \mathrm{eV})$, the $\Delta \mathrm{VB}(0.2 \mathrm{eV})$, and the bulk Si band gap $(1.1 \mathrm{eV})$ is found to be $1.8 \pm 0.1 \mathrm{eV}$, in excellent agreement, within the experimental errors, with the $1.7 \pm 0.1 \mathrm{eV}$ value of the band gap measured by PL. The band gap value reflects both the strong confinement regime and the surface chemistry effects. Moreover, these experimental data clearly indicate that there is an asymmetric shift of the Si ncs band edges in the $\mathrm{SiO}_{2}$ matrix host with respect to the bulk $\mathrm{Si} / \mathrm{SiO}_{2}$ interface. In particular, the $\Delta \mathrm{CB}(0.5 \mathrm{eV})$ is larger than the $\Delta \mathrm{VB}(0.2 \mathrm{eV})$ as already predicted by different theoretical works. $5,6,24,25$

In conclusion, we have measured the energy band alignment of $\mathrm{Si}$ ncs hosted in $\mathrm{SiO}_{2}$ by combining various standard electro-optical techniques. This achievement paves the way to a systematic investigation of the evolution of band alignment of $\mathrm{Si}$ ncs in $\mathrm{SiO}_{2}$ as a function of $\mathrm{Si}$ ncs band gap by properly tuning their dimensions.

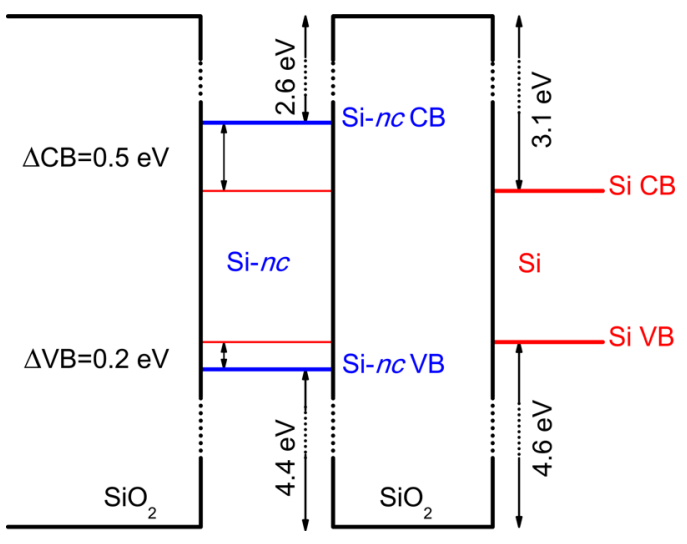

FIG. 4. (Color online) Band diagrams of the $2.6 \mathrm{~nm}$ diameter Si ncs embedded in $\mathrm{SiO}_{2}$ according to the data measured by means of C-S, PI/PN, and PL.

This research activity has been funded by the "NanoSciE+" consortium through the NANO-BLOCK project. Sabina Spiga (MDM, IMM-CNR) is acknowledged for fruitful discussions.

${ }^{1}$ S. Tiwari, F. Rana, H. Hanafi, A. Hartstein, E. F. Crabbè, and K. Chan, Appl. Phys. Lett. 68, 1377 (1996).

${ }^{2}$ S. Tiwari, F. Rana, K. Chan, L. Shi, and H. Hanafi, Appl. Phys. Lett. 69, 1232 (1996).

${ }^{3}$ N. Daldosso and L. Pavesi, Laser Photon. Rev. 3, 508 (2009).

${ }^{4}$ G. F. Brown and J. Wu, Laser Photon. Rev. 3, 394 (2009).

${ }^{5}$ E. G. Barbagiovanni, L. V. Goncharova, and P. J. Simpson, Phys. Rev. B 83, 03512 (2011).

${ }^{6}$ M. I. Alonso, I. C. Marcus, M. Garriga, A. R. Goni, J. Jedzrejewski, and I. Balberg, Phys. Rev. B 82, 045302 (2010).

${ }^{7}$ B. Garrido, M. Lopez, O. Gonzalez, A. Perez-Rodriguez, J. R. Morante, and C Bonafos, Appl. Phys. Lett. 77, 3143 (2000).

${ }^{8}$ O. Jambois, H. Rinnert, X. Devaux, and M Vergnat, J. Appl. Phys. 98, 046105 (2005).

${ }^{9}$ T. Z. Lu, M. Alexe, R. Scholz, V. Talalaev, R. J. Zhang, and M Zacharias, J. Appl. Phys. 100, 014310 (2006).

${ }^{10}$ G. Seguini, M. Perego, and M. Fanciulli, "Rare earth oxide thin films," Topics in Applied Physics, edited by G. Scarel and M. Fanciulli (Springer, Berlin, 2007), Vol. 106, pp. 269-283.

${ }^{11}$ G. Seguini, E. Bonera, S. Spiga, G. Scarel, and M. Fanciulli, Appl. Phys. Lett. 85, 5316 (2004).

${ }^{12}$ G. Seguini, S. Spiga, E. Bonera, M. Fanciulli, A. R. Huamantinco, C. J. Forst, C. R. Ashman, P. E. Blochl, A. Dimoulas, and G. Mavrou, Appl. Phys. Lett. 88, 202903 (2006).

${ }^{13}$ V. V. Afanas'ev and A. Stesmans, J. Appl. Phys. 102, 081301 (2007).

${ }^{14}$ V. V. Afans'ev, A. Stesmans, F. Chen, X. Shi, and S. A. Campbell, Appl. Phys. Lett. 81, 1053 (2002).

${ }^{15}$ V. V. Afanas'ev, M. Houssa, A. Stesmans, and M. M. Heyns, Appl. Phys. Lett. 78, 3073 (2001).

${ }^{16}$ V. V. Afanas'ev and A. Stesmans, Phys. Rev. B 59, 2025 (1999).

${ }^{17}$ V. V. Afanas'ev, M. Badylevich, A. Stesmans, A. Laha, H. J. Osten, and A. Fissel, Appl. Phys. Lett. 95, 102107 (2009).

${ }^{18}$ C.-H. Cho, B.-H. Kim, S.-K. Kim, and S.-J. Park, Appl. Phys. Lett. 96, 223110 (2010).

${ }^{19}$ M. Zacharias, J. Heitmann, R. Scholz, U. Kahler, M. Schmidt, and J. Blasing, Appl. Phys. Lett. 80, 661 (2002).

${ }^{20}$ S. Schamm, C. Bonafos, H. Coffin, N. Cherkashin, M. Carrada, G. B. Assayag, A. Claverie, M. Tencé, and C. Colliex, Ultramicroscopy 108, 346 (2008).

${ }^{21}$ B. J. Hinds, T. Yamanaka, and S. Oda, J. Appl. Phys. 90, 6402 (2001).

${ }^{22}$ E. H. Nicollian and J. R. Brews, Metal Oxide Semiconductor Physics and Technology (Wiley, New York, 1982).

${ }^{23}$ R. G. Southwick and W. B. Knowlton, IEEE Trans. Device Mater. Reliab. 6, 136 (2006).

${ }^{24}$ A. Sa'ar, Y. Reichman, M. Dovrat, D. Jrapf, J. Jedzrejewski, and I. Balberg, Nano Lett. 5, 2443 (2005).

${ }^{25}$ C. Bulutay, Phys. Rev. B 76, 205321 (2007). 